\title{
Evaluation of Lumbar Disc Herniation on Magnetic Resonance Imaging (MRI)
}

\author{
Sohail Nazeer* \\ Student, Superior College Lahore, University Campus, 17-KM Raiwaind Road, Kot Arain, Lahore, Pakistan \\ Tayyaba Qadeer \\ Student, Superior College Lahore, University Campus, 17-KM Raiwaind Road, Kot Arain, Lahore, Pakistan \\ Amna Farooq \\ Student, Superior College Lahore, University Campus, 17-KM Raiwaind Road, Kot Arain, Lahore, Pakistan
}

Mahanoor Naseem

Student, Superior College Lahore, University Campus, 17-KM Raiwaind Road, Kot Arain, Lahore, Pakistan

Jahanzaib Ahmad

Student, Superior College Lahore, University Campus, 17-KM Raiwaind Road, Kot Arain, Lahore, Pakistan

Utrooba Shahid

Lecturer, Superior College Lahore, University Campus, 17-KM Raiwaind Road, Kot Arain, Lahore, Pakistan

Ather Shams Rana

Lecturer, Superior College Lahore, University Campus, 17-KM Raiwaind Road, Kot Arain, Lahore, Pakistan

Hafiz Muhammad Rizwan

Lecturer, Superior College Lahore, University Campus, 17-KM Raiwaind Road, Kot Arain, Lahore, Pakistan

Amna Babar

Lecturer, Superior College Lahore, University Campus, 17-KM Raiwaind Road, Kot Arain, Lahore, Pakistan

Rana Muhammad Bakhtawar Khan Sajawal

Lecturer, Superior College Lahore, University Campus, 17-KM Raiwaind Road, Kot Arain, Lahore, Pakistan

The research is financed by Asian Development Bank. No. 2006-A171(Sponsoring information)

Abstract

OBJECTIVE: To evaluate the lumbar disc herniation on magnetic resonance imaging (MRI)

BACK GROUND: Lumbar disk herniation (LDH) is a common cause of low back pain in the world. The evidence has shown that the incidence of lumbar disc herniation (LDH) increases with age, weight lift and also depend on gender. In this cross-sectional descriptive study of LDH has been conducted to investigate the role of age in the incidence of LDH in elderly. The aim of the study is to investigate the relationship between the process of aging and the occurrence of LDH in old adults. Clinical studies have indicated that morphological characteristics of lumbar discs and signal intensity of patient's MRI image have close relationship with clinical outcome

Keywords: Intervertebral Disc, Herniated Disc, Protrusion, Degenerative Disc

DOI: $10.7176 / \mathrm{JHMN} / 90-07$

Publication date:June $30^{\text {th }} 2021$

\section{INTRODUCTION:}

Herniation is a medical term in which there is localized displacement of disc material (annular fibrosis and nucleus pulposus) beyond the limits of intervertebral disc space. ${ }^{1}$

The lumbar section of the spine consists of five vertebrae (L1-L5) and five intervertebral discs, and extends from the bottom of the thoracic spine to the beginning of the sacrum, which attaches the spine to the pelvis. The major functions of lumbar spine include heavy load bearing and protection of the spinal cord during locomotion and torsion of the trunk, providing maximum stability while maintain crucial mobility of the trunk about the hips/pelvis. ${ }^{2}$ The lumbar vertebrae have many features different from those typical of cervical or thoracic vertebrae. The most notable difference is the presence of a large vertebral body. ${ }^{3}$ The intervertebral disc is a highly organized matrix laid down by relatively few cells in a specific manner. The central gelatinous nucleus pulposus is retain within the more collagenous anulus fibrosus laterally and the cartilage end plates inferiorly and superiorly. ${ }^{4}$ The prevalence rate of intervertebral disc herniation of the thoracic spine is rare compared to that of the cervical or 
lumbar spine. ${ }^{5}$ In 2013, prevalence of symptomatic herniated lumbar disc is about $1-3 \%$ in Finland and Italy, depending on age and sex. The highest prevalence of lumbar disc herniation is among people aged 30-50 years, with a male to female ratio of 2:1. In people aged $25-55$ years, about $95 \%$ of herniated discs occur at the lower lumbar spine (L4/L5 and L5/S1 level). ${ }^{6}$

The pathophysiology of herniated discs is concentration of proteoglycans decreases and proportion of collagen increases in nucleus pulposus, water binding capability of the nucleus decreases and nucleus become more fibrous and stiffer. Due to this the nucleus is less able to bear and disburse load, transferring load to the posterior annulus. The most common cause of disc herniation is a degenerative process in which, as the nucleus pulposus becomes less hydrated, human age, weakens, trauma and low back pain (backache). Degenerative disc disease is occurring when one or more of the discs that lies between the vertebrae of the spine begin to dehydrated, shrink or compress. The fluid present within the nucleus pulposus gradually dries out and as the disc loses hydration, it offers less cushioning and becomes more prone to tears. Herniated discs can be categorized as protrusion, extrusion, or sequestration disc herniation. Protrusion occurs when some inner fibers of the annulus tear but the outer layers remain intact the nucleus can focally herniate through the inner tear. Protrusions is the wide-based herniations in which the diameter at the base of the herniation is wider than the diameter of the herniation in the canal. The percentage of protruded disc is $70-80 \%$. The extrusions have a narrow base, with a large herniation in the canal, and sequestrations are herniations in which there is no continuity between the herniation and the remaining intervertebral disc. ${ }^{7}$ A herniated disc extrusion occurs when the nucleus pulposus herniates through a complete tear of the annulus fibrosis and is contained only by the posterior longitudinal ligament. ${ }^{8}$ In extrusion the length of the base is less than the height of the hernia. ${ }^{9}$ The percentage of extruded disc is $30-40 \%$ while sequestrated disc is less than $10 \%$. Risk factors include male gender, age (30-50 years), heavy lifting or twisting and stressful occupation. Symptoms typically commence with a period of backache followed by sciatica. There may be paresthesia in unilateral and bilateral legs and feet, pain radiating towards unilateral and bilateral legs and feet's, motor weakness, loss of reflexes. ${ }^{10}$ The primary signs and symptoms of LDH are radicular pain, sensory abnormalities, and weakness in the distribution of one or more lumbosacral nerve roots. Focal immobility, restricted trunk flexion, and increases in leg pain with straining, coughing, and sneezing are also indicative. Patients frequently report increased pain when sitting, which is known to increase disc pressure by nearly $40 \%$. In paracentral herniations, the trans versing nerve root is affected versus in far lateral herniations, the exiting nerve root is affected. Such as in a paracentral herniation at L4-5 would cause L5 radiculopathy whereas a far lateral herniation at the same level would cause L4 radiculopathy. ${ }^{11}$ The pain that is relieved with sitting for forward flexion are more consistent with lumbar spinal stenosis (LSS), as the latter motion increases disc pressure by $100-400 \%$ and would likely increase pain in isolated LDH. An annular tear is disruption of concentric collagen fibers comprising the annulus fibrosis. The percentage of annular tear in herniated disc disease is $60-70 \%$. Annular tears can be categorized as concentric tears, radial tears and transverse tears. Concentric tears are circumferential tear which are found in the outer layer of annular wall. Radial tears begin at the innermost portion of the annulus and center of the disc. Transverse tears are also known as peripheral tears and rim lesions because it begins tear in the outermost rim of the disc. Patients with lumbar disc degenerative disease can be presented with sensory disturbances in legs, paresthesia in unilateral and bilateral legs and feet's, muscle weakness, claudication and pain is often worse while sitting, bending, lifting or twisting. There are many risk factors associated with the lumbar disc degenerative disease like advancing age, obesity, trauma, heavy weight lifting. ${ }^{12}$ Lower back pain, the leading cause of workplace absences and disability, is often attributed to intervertebral disc degeneration, in which nucleus pulposus (NP) herniates through lesions in the annulus fibrosus (AF) and impinges on the spinal cord and surrounding nerves. ${ }^{13}$

MRI is a gold standard diagnostic tool for the evaluation of lumbar disc containment and it is a wellestablished method for the evaluation of disc herniation. ${ }^{14}$ Morphological axial and sagittal T1-T2-weighted and STIR imaging are standard diagnostic methods for disc herniation and degenerative disc disease. ${ }^{15}$ The slice thickness for lumbar disc herniation is $2-3 \mathrm{~mm}$ and gap is $0.3 \mathrm{~mm}$. In sagittal T2 weighted image of MRI, the nucleus pulposus appears hyper intense while the surrounding annulus fibrosus appears hypo intense. However, a herniated disc appears dark. Magnetic resonance imaging (MRI) has become a valuable noninvasive, cost-effective tool for accurately evaluating spine disorders. ${ }^{16}$ Magnetic resonance imaging allows better visualization of the spinal cord, ligaments, discs, vessels, and others soft tissues than computerized tomography (CT) scans or radiographs. ${ }^{17}$

\subsection{MATERIAL AND METHOD}

A cross sectional descriptive study was conducted at Punjab radiology imaging center LAHORE PAKISTAN, between February 2021 to May2021. Over a 4 months periods,50 patient sampled with lumbar disc herniation were included in this study. All the patient were subjected to a 1.5 Tesla MRI scan. Out of total patients for low back ache with neurological deficits. $100 \%$ patient present with protuted disc herniation.

\subsubsection{DISCUSSION}

Our medical investigation has presented that the clinical appearance of LDH patients was varied and that the most 
collective site of LDH is near the bottom of the spine at L4-L5 and L5-S1. Opposing to past reports that the frequency of LDH rises with aging, this study has found that the occurrence of LDH has a downward trend with aging in the elderly, especially after 50 years old. Abnormal activities, such as repetitive bending, twisting, and lifting, can increase abnormal pressure on the nucleus of the disc and injure the annulus, leading to herniation. LDH occurs as a result of unexpected stress, such as from an accident and trauma. Poor body posture and incorrect lifestyle can place additional stress on the lumbar spine. With aging, discs progressively dry out, lose their strength and resiliency, and easily convince the occurrence of herniation. Though, our clinical examination has associated that the occurrence of LDH decreases with aging in the elderly population, particularly after 60 years old. Therefore, we hypothesized that the volume and inflammation of the nucleus gets lesser since degeneration contributes to atrophy of the nucleus with the aging process. Thus, the pressure from the nucleus will become progressively less, with the result being lower frequency of annulus injury and occurrence of LDH, especially after 50 years old. It appears that the inflammatory consequence of the nucleus is stronger than degeneration, and the incidence of LDH is greater before 50 years of age. This examination additional recommends that surgery is not preferred in elderly patients with LDH. If it is not a case of acute nerve and spinal cord compression, nonoperative treatment will be used with elderly patients of $\mathrm{LDH}$, such as physical therapy and pain medications. Adults typically have more herniated disc levels (mostly protrusions). It is better that old adult patients with LDH are treated in a therapy center if they present with degenerative changes. As age progresses, the volume of the nucleus becomes smaller, and the pressure from the nucleus is reduce. This study also provides new reflection for the future treatment of LDH in the elderly population.

\subsubsection{RESULTS:}

According to our results lumbar disc herniation was highly recorded in males at the age of 60 years and in females at the age of 35 years. 27 males and 23 females are noted with lumbar disc herniation. The maximum herniation is found amongst people age 30-50 years, with a male to female ratio $2: 1$. The most common site of lumbar disc herniation was noted at L5/S1 level of intervertebral disc and most common type of disc herniation is Protrusion mostly noted in patients. According to our results the physical activity level (low or mild) is highly noted in those patients who have advancing age, history of trauma and accidents.

\section{TABLE:}

\section{PHYSICAL ACTIVITY LEVEL:}

\begin{tabular}{|l|l|}
\hline PAL & DETAILS \\
\hline Low/ mild & House wife, advancing age and history of trauma. \\
\hline $\begin{array}{l}\text { Moderately } \\
\text { active }\end{array}$ & Heavy weight lifting and twisting, stressful occupation etc. \\
\hline $\begin{array}{l}\text { Highly/vigorously } \\
\text { active }\end{array}$ & $\begin{array}{l}\text { Racing, jogging etc. those who perform high level of physical activity such as agricultural } \\
\text { workers and laborers etc. }\end{array}$ \\
\hline
\end{tabular}

NONE $=0$

LOW $=1$

MODERATE $=2$

HIGHLY ACTIVE $=3$

Level of Vertebrae * Physical activity Level

Crosstab

\begin{tabular}{|c|c|c|c|c|c|c|}
\hline & & & \multicolumn{3}{|c|}{ Physical activity Level } & \multirow[b]{2}{*}{ Total } \\
\hline & & & Low and Mild & $\begin{array}{l}\text { Moderately } \\
\text { Active }\end{array}$ & $\begin{array}{l}\text { Highly } \\
\text { Active }\end{array}$ & \\
\hline \multirow[t]{4}{*}{ Level of Vertebrae } & \multirow[t]{2}{*}{ Absent } & Count & 13 & 6 & 2 & 21 \\
\hline & & Expected Count & 13.0 & 5.9 & 2.1 & 21.0 \\
\hline & \multirow[t]{2}{*}{ Present } & Count & 18 & 8 & 3 & 29 \\
\hline & & Expected Count & 18.0 & 8.1 & 2.9 & 29.0 \\
\hline \multirow[t]{2}{*}{ Total } & & Count & 31 & 14 & 5 & 50 \\
\hline & & Expected Count & 31.0 & 14.0 & 5.0 & 50.0 \\
\hline
\end{tabular}


Chi-Square Tests

\begin{tabular}{lr|r|r} 
& Value & & \multicolumn{2}{c}{$\begin{array}{c}\text { Asymptotic Significance } \\
\text { (2-sided) }\end{array}$} \\
\hline Pearson Chi-Square & $.012^{\mathrm{a}}$ & 2 & .994 \\
\hline Likelihood Ratio & .013 & 2 & .994 \\
\hline Linear-by-Linear Association & .001 & 1 & .973 \\
\hline N of Valid Cases & 50 & & \\
\hline
\end{tabular}

a. 2 cells (33.3\%) have expected count less than 5 . The minimum expected count is 2.10 .

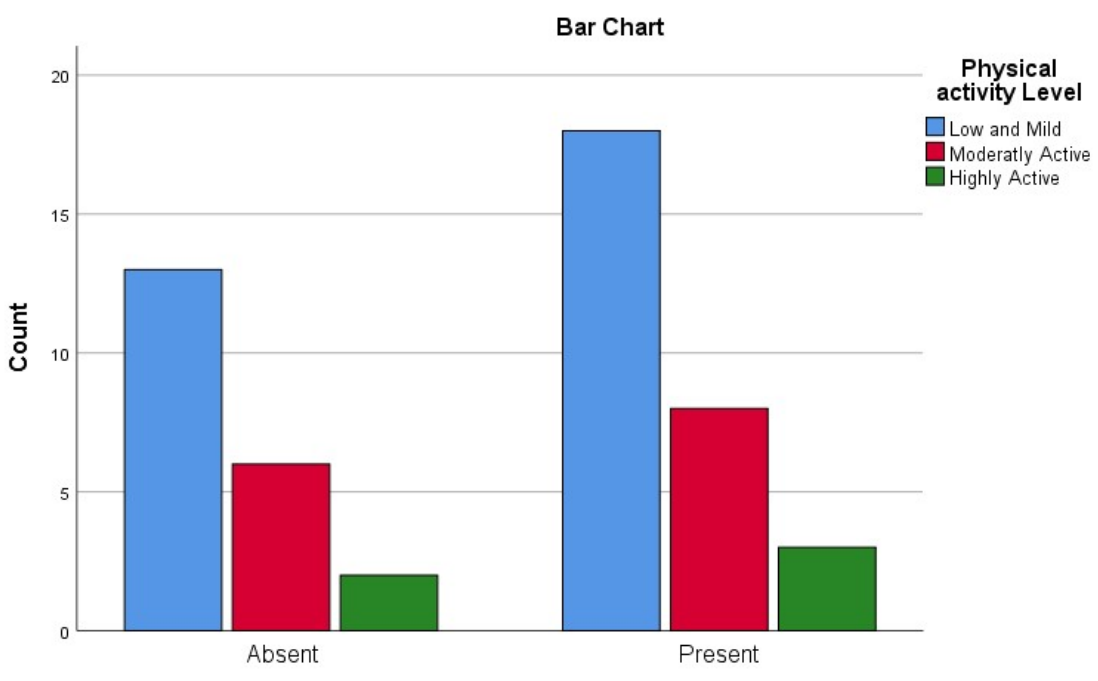

L4L5

Case Processing Summary

\begin{tabular}{|c|c|c|c|c|c|c|c|c|}
\hline & \multicolumn{6}{|c|}{ Cases } \\
\hline & & & \multicolumn{2}{|c|}{ Valid } & \multicolumn{2}{|c|}{ Missing } & \multicolumn{2}{|c|}{ Total } \\
\hline & & & $\mathrm{N}$ & Percent & $\mathrm{N}$ & Percent & $\mathrm{N}$ & Percent \\
\hline $\begin{array}{l}\text { Gait Condition } \\
\text { Severity }\end{array}$ & $*$ & Pain & 50 & $100.0 \%$ & 0 & $0.0 \%$ & 50 & $100.0 \%$ \\
\hline
\end{tabular}

Gait Condition * Pain Severity Crosstabulation

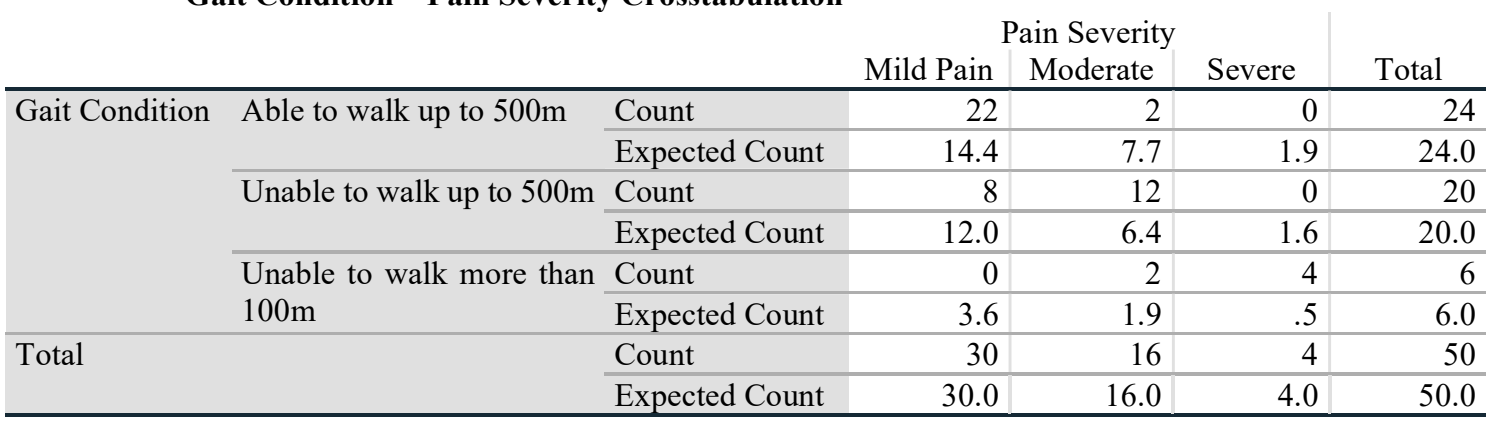

\section{Chi-Square Tests}

\begin{tabular}{lr|r|r} 
& Value & df & $\begin{array}{c}\text { Asymptotic Significance } \\
\text { (2-sided) }\end{array}$ \\
\hline Pearson Chi-Square & $47.382^{\mathrm{a}}$ & 4 & .000 \\
\hline Likelihood Ratio & 38.990 & 4 & .000 \\
\hline Linear-by-Linear Association & 28.167 & 1 & .000 \\
\hline N of Valid Cases & 50 & & \\
\hline
\end{tabular}

a. 5 cells $(55.6 \%)$ have expected count less than 5 . The minimum expected count is .48 . 
Symmetric Measures

\begin{tabular}{llr|r}
\hline & Value & & Approximate Significance \\
\hline Nominal by Nominal & Phi & .973 & .000 \\
\cline { 2 - 4 } & Cramer's V & .688 & .000 \\
\hline N of Valid Cases & 50 & \\
\hline
\end{tabular}

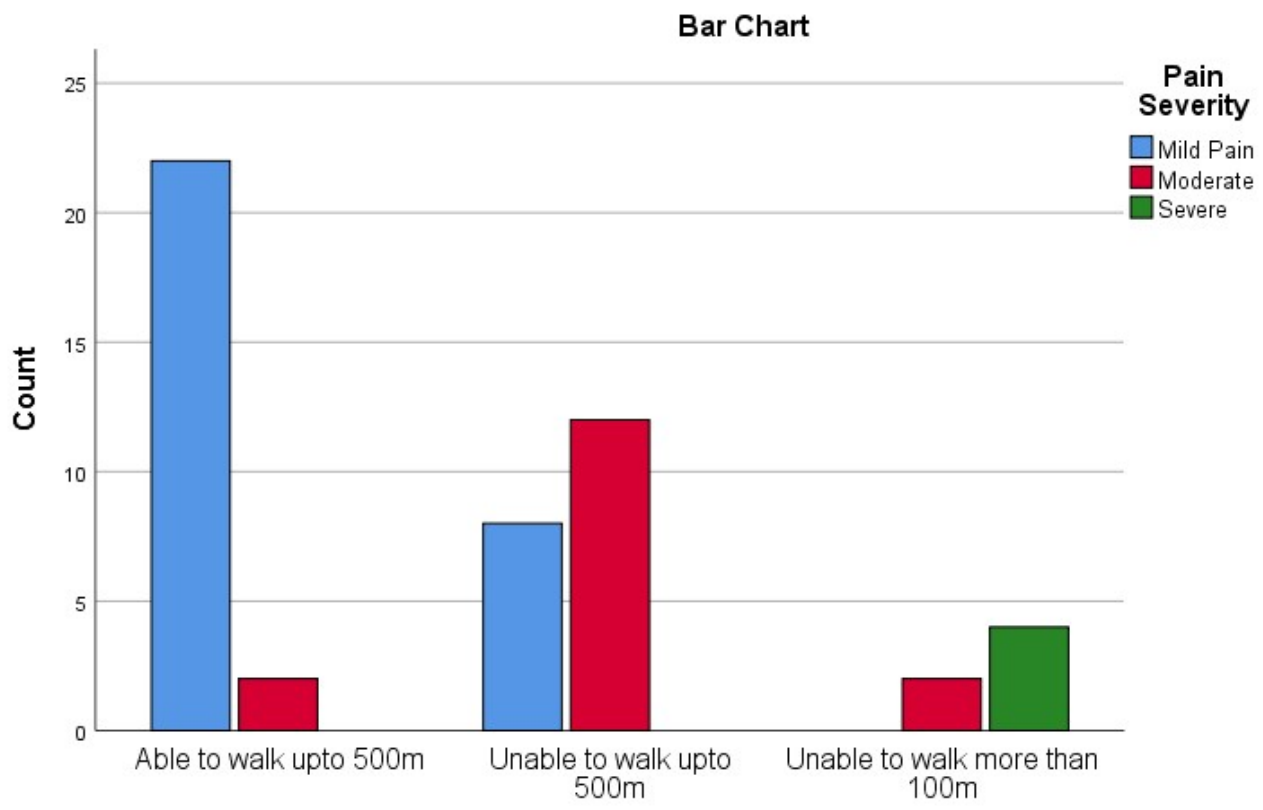

Gait Condition

\section{Crosstabs}

Case Processing Summary

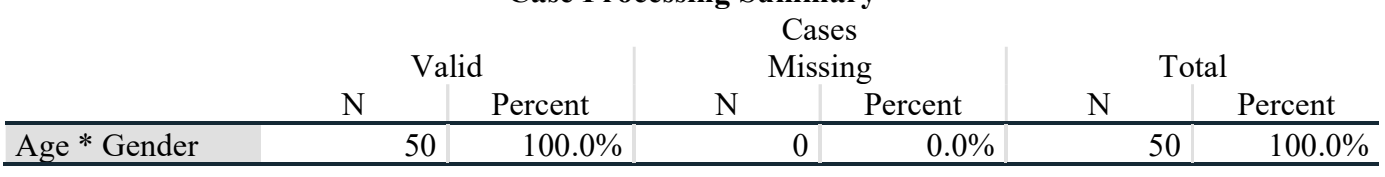




\begin{tabular}{|c|c|c|c|c|}
\hline \multirow{3}{*}{ Count } & \multicolumn{4}{|c|}{ Age * Gender Crosstabulation } \\
\hline & & \multicolumn{2}{|c|}{ Gender } & \multirow[b]{2}{*}{ Total } \\
\hline & & Male & Female & \\
\hline \multirow[t]{33}{*}{ Age } & 18 & 1 & 0 & 1 \\
\hline & 22 & 0 & 1 & 1 \\
\hline & 23 & 1 & 0 & 1 \\
\hline & 27 & 1 & 0 & 1 \\
\hline & 28 & 1 & 0 & 1 \\
\hline & 29 & 0 & 2 & 2 \\
\hline & 30 & 0 & 1 & 1 \\
\hline & 31 & 1 & 1 & 2 \\
\hline & 32 & 2 & 0 & 2 \\
\hline & 35 & 2 & 3 & 5 \\
\hline & 36 & 1 & 1 & 2 \\
\hline & 37 & 1 & 0 & 1 \\
\hline & 38 & 0 & 1 & 1 \\
\hline & 39 & 0 & 1 & 1 \\
\hline & 40 & 1 & 0 & 1 \\
\hline & 41 & 1 & 1 & 2 \\
\hline & 42 & 1 & 1 & 2 \\
\hline & 43 & 2 & 1 & 3 \\
\hline & 44 & 0 & 1 & 1 \\
\hline & 45 & 1 & 0 & 1 \\
\hline & 48 & 1 & 0 & 1 \\
\hline & 49 & 0 & 1 & 1 \\
\hline & 50 & 1 & 1 & 2 \\
\hline & 52 & 0 & 1 & 1 \\
\hline & 54 & 0 & 1 & 1 \\
\hline & 55 & 1 & 0 & 1 \\
\hline & 56 & 1 & 0 & 1 \\
\hline & 58 & 0 & 1 & 1 \\
\hline & 60 & 3 & 1 & 4 \\
\hline & 67 & 0 & 1 & 1 \\
\hline & 68 & 1 & 0 & 1 \\
\hline & 70 & 1 & 1 & 2 \\
\hline & 78 & 1 & 0 & 1 \\
\hline Total & & 27 & 23 & 50 \\
\hline
\end{tabular}



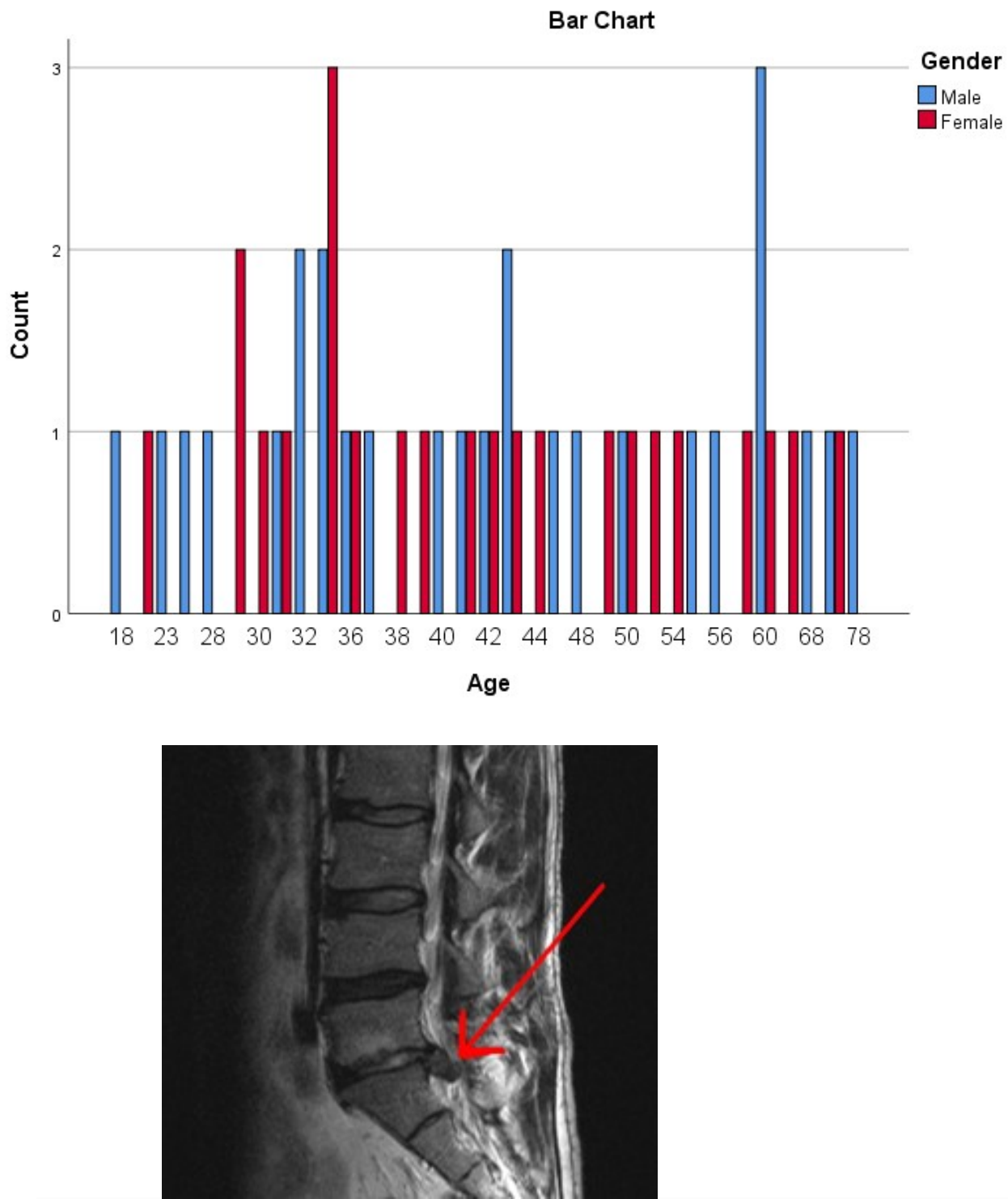

A 38-year-old man was affected by chronic low back pain radiating to the gluteal area, posterior aspect of the thigh, and anterolateral side of the right leg.On MRI the lumbar area revealed a disc herniation at the L4-5 level. 

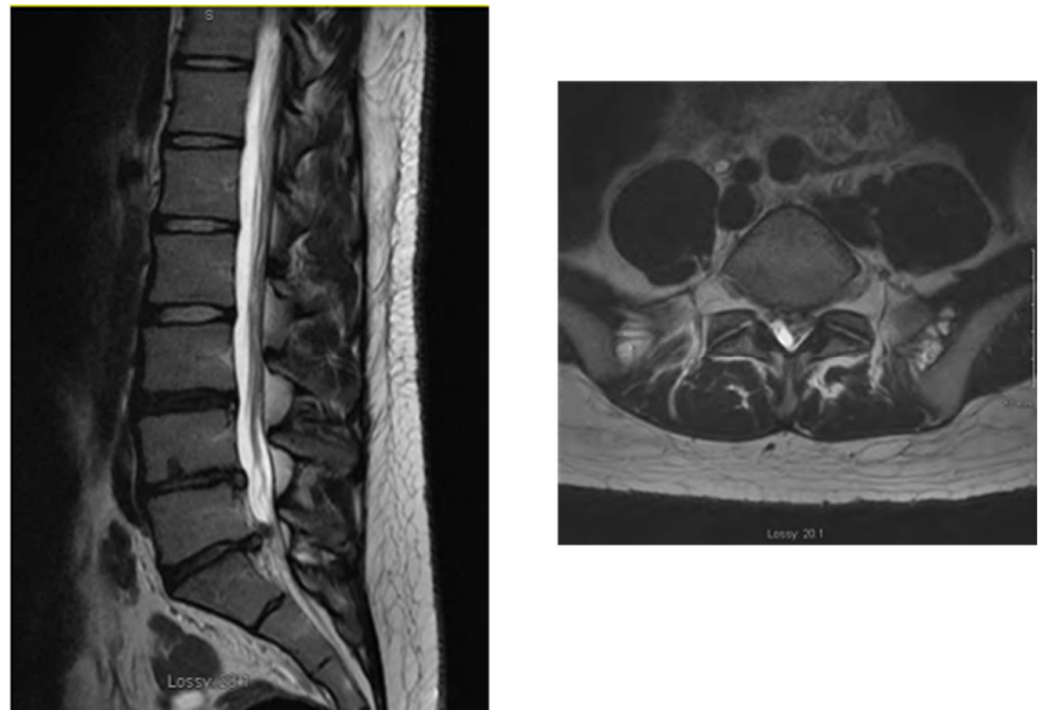

The patient is a 60-year-old female with severe low back pain and left leg numbness and weakness after a martial arts class. Sagittal and axial MRI sections showing left paracentral L5-S1 disc herniation with extruded fragment compressing the nerve.

\section{CONCLUSION(S)}

A declining occurrence of LDH with aging happens in elderly. This examination specifies that aging is not a provider to the performance of $\mathrm{LDH}$ in the elderly while the frequency of $\mathrm{LDH}$ is related to age.

\section{References}

1) Jordon J, Konstantinou K, O'Dowd J. Herniated lumbar disc. BMJ clinical evidence. 2009;2009

2) Frost BA, Camarero-Espinosa S, Foster EJ. Materials for the spine: anatomy, problems, and solutions. Materials. 2019 Jan;12(2):253.

3) Waxenbaum JA, Reddy V, Williams C, Futterman B. Anatomy, back, lumbar vertebrae. StatPearls [Internet]. 2020 Aug 10.

4) Roberts S, Evans H, Trivedi J, Menage J. Histology and pathology of the human intervertebral disc. JBJS. 2006 Apr 1;88(suppl_2):10-

5) Son ES, Lee SH, Park SY, Kim KT, Kang CH, Cho SW. Surgical treatment of t1-2 disc herniation with t1 radiculopathy: A case report with review of the literature. Asian spine journal. 2012 Sep;6(3):199.

6) Laxmaiah Manchikanti, An Update of Comprehensive Evidence-Based Guidelines for Interventional Techniques in Chronic Spinal Pain and disc herniations. Part II: Guidance and Recommendations. Pain Physician 2013

7) Schroeder GD, Guyre CA, Vaccaro AR. The epidemiology and pathophysiology of lumbar disc herniations. InSeminars in Spine Surgery 2016 Mar 1 (Vol. 28, No. 1, pp. 2-7). WB Saunders

8) MAMATAZ A, RABBI AF, RAHMAN MK, SARKAR R, NABI S, AHMED S, CHOWDURY F, YASMIN T. Diagnostic Performance of Magnetic Resonance Imaging in Lumbar Disc Herniation. BANGLADESH JOURNAL OF RADIOLOGY AND IMAGING. 2015 Jan; 23:3.

9) Vialle LR, Vialle EN, Suárez Henao JE, Giraldo G. LUMBAR DISC HERNIATION. Rev Bras Ortop. 2015;45(1):17-22. Published 2015 Nov 16. doi:10.1016/S2255-4971(15)30211-1

10) MAMATAZ A, RABBI AF, RAHMAN MK, SARKAR R, NABI S, AHMED S, CHOWDURY F, YASMIN T. Diagnostic Performance of Magnetic Resonance Imaging in Lumbar Disc Herniation. BANGLADESH JOURNAL OF RADIOLOGY AND IMAGING. 2015 Jan;23:3

11) Amin RM, Andrade NS, Neuman BJ. Lumbar disc herniation. Current reviews in musculoskeletal medicine. 2017 Dec;10(4):507-16

12) Suthar P, Patel R, Mehta C, Patel N. MRI evaluation of lumbar disc degenerative disease.Journal of clinical and diagnostic research: JCDR. 2015 Apr;9(4):TC04.

13) Sloan Jr SR, Lintz M, Hussain I, Hartl R, Bonassar LJ. Biologic annulus fibrosus repair: a review of preclinical in vivo investigations. Tissue Engineering Part B: Reviews. 2018 Jun 1;24(3):179-90.

14) Hoppe S, Quirbach S, Mamisch TC, Krause FG, Werlen S, Benneker LM. Axial T2* mapping in intervertebral discs: a new technique for assessment of intervertebral disc degeneration. European radiology. 2012 Sep 1;22(9):2013-9. 
15) Hoppe S, Quirbach S, Mamisch TC, Krause FG, Werlen S, Benneker LM. Axial T2* mapping in intervertebral discs: a new technique for assessment of intervertebral disc degeneration. European radiology. 2012 Sep 1;22(9):2013-9.

16) Kasdan RB, Howard JL. Neuroimaging of spinal diseases: a pictorial review. InSeminars in neurology 2008 Sep (Vol. 28, No. 04, pp. 570-589). (C) Thieme Medical Publishers

17) Bozzo A, Marcoux J, Radhakrishna M, Pelletier J, Goulet B. The role of magnetic resonance imaging in the management of acute spinal cord injury. Journal of neurotrauma. 2011 Aug 1;28(8):1401-11. 